\title{
La aportación de los repertorios lexicográficos bilingües (español- italiano) en el proceso de descodificación y traducción de unidades fraseológico-idiomáticas relacionadas con las partes del cuerpo: hacia una equivalencia traductológica
}

\author{
Giuseppe Trovato ${ }^{1}$
}

Recibido: 23 de noviembre de 2018 / Modificado: 18 de febrero de 2019 / Aceptado: 27 de febrero de 2019

\begin{abstract}
Resumen. El diccionario -concebido como repertorio lexicográfico bilingüe- siempre ha sido considerado como la herramienta de consulta más inmediata y rentable por parte del traductor. Sin embargo, cualquiera que haya emprendido alguna vez la actividad traductora, se habrá percatado de los límites que plantea dicha herramienta. Con este artículo nos proponemos analizar el tratamiento de una serie de unidades fraseológicas con carácter idiomático relacionadas con las partes del cuerpo y examinar en qué medida el diccionario bilingüe puede facilitar la tarea de comprensión y de transposición interlingüística (en la dirección español $>$ italiano). Tomaremos como punto de referencia cuatro diccionarios bilingües usados en la sincronía actual. Así pues, tras llevar a cabo un rastreo terminológico de las expresiones examinadas, estudiaremos cómo cada una de las cuatro herramientas lexicográficas aborda la equivalencia traductológica y reflexionaremos en torno al grado de eficacia comunicativa en la lengua de llegada a raíz del acto traductor. Esta labor de consulta planteará una serie de interrogantes acerca de la rentabilidad de los diccionarios bilingües a la hora de descodificar correctamente el significado de unidades fraseológico-idiomáticas y de dar con una equivalencia traductológica acertada. Palabras clave: Lexicografía bilingüe, unidades fraseológico-idiomáticas, las partes del cuerpo, equivalencia traductológica.
\end{abstract}

\section{[en] The contribution of bilingual dictionaries (Spanish-Italian) in the process of decoding and translating phraseological-idiomatic units related to the parts of the body: Towards a translatological equivalence}

\begin{abstract}
A dictionary has always been a valuable tool for a translator due to its immediateness in terms of consulting. However, translators have complete awareness of the limits of this lexical tool.

This paper aims to analyse how a series of phraseological items related to the parts of the body are treated and translated from Spanish into Italian in four Spanish-Italian dictionaries. After carrying out a terminological analysis of the expressions examined, we will study how each of the four dictionaries deals with the translation equivalence and we will reflect on the degree of communicative effectiveness in Italian as a result of the translation process. Our analysis will raise a series of questions about the profitability of bilingual dictionaries when correctly deciphering the meaning of phraseological and idiomatic units and finding a correct translatological equivalence.
\end{abstract}

Key words: Bilingual lexicography, phraseological-idiomatic units, parts of the body, translatological equivalence.

1 Università Ca' Foscari Venezia. Dipartimento di Studi Linguistici e Culturali Comparati, Dorsoduro 3299, Calle Bernardo, 30123 - Venezia.

giuseppe.trovato@unive.it 
Sommario: 1. Introducción 2. Fraseología y Traducción: ¿unión consustancial o relación imposible? 3. La contribución de los diccionarios bilingües en el proceso de descodificación y traducción de las unidades fraseológicas 4. Hacia una equivalencia traductológica: estudio lexicográfico bilingüe de unidades fraseológico-idiomáticas relacionadas con las partes del cuerpo. 4.1. Metodología del estudio lexicográfico 4.2. Indicaciones metodológicas acerca del tratamiento de la fraseología en los diccionarios objeto de estudio 5. Análisis lexicográfico y traductológico de 20 unidades fraseológicoidiomáticas relacionadas con las partes del cuerpo 6. Comentario sobre el estudio lexicográfico y consideraciones finales.

Cómo citar: Trovato, Giuseppe (2019): «La aportación de los repertorios lexicográficos bilingües (español-italiano) en el proceso de descodificación y traducción de unidades fraseológico-idiomáticas relacionadas con las partes del cuerpo: hacia una equivalencia traductológica», Cuadernos de Filología Italiana, 26, pp. 93-117.

\section{Introducción}

Por lo general la lengua se puede considerar como la manifestación más evidente de una idiosincrasia cultural. No obstante, dicha idiosincrasia en muchas ocasiones conlleva una opacidad lingüística, fruto de la manera en que los hablantes nativos tienden a combinar las palabras en el marco de sus enunciados lingüísticos. De ahí que no se pueda afirmar, bajo ningún concepto, que la lengua sea transparente, pues encierra matices semánticos que van más allá de la superficie de las palabras y afecta a la dimensión social y pragmática de la comunicación.

Lo anteriormente mencionado remite inevitablemente a lo que podemos calificar de fenómeno fraseológico. A este respecto, Corpas Pastor (2003: 337) apunta acertadamente que: «El dominio del componente fraseológico es uno de los indicadores más claros de uso nativo de un idioma». Cuantos más modismos, locuciones fijas y expresiones idiomáticas un aprendiente de un idioma extranjero vaya incorporando a su caudal léxico, más elevada resultará su competencia fraseológica y, en última instancia, su dominio de la lengua extranjera.

En la estela de estas notas introductorias, en este artículo pretendemos llevar a cabo un estudio encaminado a vislumbrar qué contribución pueden ofrecer los repertorios lexicográficos bilingües español-italiano a la hora de localizar equivalencias traductológicas acertadas en el ámbito de la fraseología contrastiva. Nuestro foco de interés e investigación serán las expresiones idiomáticas y locuciones fijas relacionadas con las partes del cuerpo, por tratarse de un asunto lingüístico muy rico tanto por su tratamiento fraseológico como traductológico.

Ahora bien, dada la amplitud del tema tratado, urge realizar algunas aclaraciones. En primer lugar, a efectos de nuestro trabajo hemos optado por ceñir nuestra atención a los repertorios lexicográficos bilingües empleados en la sincronía actual, esto es, diccionarios publicados en el siglo XXI. Sin menoscabo de los repertorios lexicográficos considerados más "antiguos" hecho de que pretendemos abordar la equivalencia traductológica en función del uso actual de la lengua. A continuación, cabe señalar que no examinaremos la totalidad

2 Los repertorios lexicográficos bilingües más relevantes que hemos calificado de "antiguos" serían los siguientes: Martínez Amador (1957); Sebastián Carbonell (1950-1957); Lucio Ambruzzi (1949); Gaetano Frisoni (1917-1927). 
de las unidades fraseológico-idiomáticas pertenecientes al corpus analizado por cuestiones de extensión del trabajo, sino que proporcionaremos una muestra lo suficientemente significativa conformada por 20 unidades fraseológicas, pertenecientes a las 20 partes del cuerpo analizadas. Por último, pero no por eso menos importante, procede destacar que, a lo largo del rastreo y cotejo terminológico, nos hemos decantado por la dirección español > italiano, por ser este último el idioma objeto de tratamiento lexicográfico y de reflexión traductológica por parte de usuarios italohablantes que usan el castellano como lengua de comunicación y traducción.

\section{Fraseología y Traducción: ¿unión consustancial o relación imposible?}

A nuestro parecer, los campos de estudio de la fraseología y de la traducción mantienen una relación consustancial, pues en su esencia se halla el carácter comparativo. Todo aprendiente de un idioma extranjero, al emplear una unidad léxica o sintagmática más o menos compleja, se plantea cómo trasladarla a la lengua objeto de estudio o bien de la lengua estudiada a su propio idioma. Los resultados, en muchas ocasiones, son nefastos dada la acusada tendencia a una transposición al pie de la letra, especialmente en el caso de lenguas filogenéticamente emparentadas. Sin embargo, precisamente en este contexto, las consecuencias de dicha tendencia se palian ya que existen casos de correspondencia total o casi total. Veamos los ejemplos siguientes:

(1) Andar con pies de plomo $=$ Andarci con i piedi di piombo

(2) Cada dos por tres $=$ Ogni due e tre

(3) Poner el dedo en la llaga $=$ Mettere il dito nella piaga

En los casos que acabamos de mostrar, cualquier hablante, ya sea italohablante o hispanohablante, no tendría ningún problema a la hora de descodificar y, de paso, traducir correctamente estas expresiones. Sin embargo, por hablar en términos idiomáticos, no es oro todo lo que reluce, puesto que se dan casos en los que la afinidad lingüística no ayuda en absoluto:

(4) Hablar por los codos = Parlare in eccesso / come una macchinetta

(5) Hacer de tripas corazón = Fare di necessità virtù

(6) No dar pie con bola = Non azzeccarne una

En estos tres últimos casos, supondría toda una proeza descifrar el correcto significado de las expresiones sin recurrir a una herramienta lexicográfica bilingüe.

Con independencia del grado de comprensibilidad de las seis expresiones indicadas, lo que sí queda claro es que estamos ante una serie de unidades fraseológicas que, siguiendo a Corpas Pastor, se configuran como:

Unidades léxicas formadas por más de dos palabras gráficas en su límite inferior. [...] se caracterizan por una alta frecuencia de uso y de coaparición de sus elemen- 
tos integrantes; por su institucionalización, entendida en términos de fijación y especialización semántica; por su idiomaticidad y variación potencial. (Corpas Pastor 1996: 20)

En Corpas Pastor (1996), hallamos con más frecuencia la denominación de "enunciado fraseológico", si bien en el ámbito de estudio del fenómeno fraseológico contamos con una plétora de etiquetas terminológicas que no ha hecho sino generar cierta confusión. Sin pretender entrar en mayores detalles acerca de esta falta de acuerdo, nos parece conveniente señalar que a lo largo de las últimas décadas del siglo pasado se llevaron a cabo diversas propuestas taxonómicas en lo relativo a la fraseología ${ }^{3}$. Pionero, en este sentido, fue Julio Casares con su Introducción a la lexicografía moderna (1950), obra en la que propuso una clasificación entre locuciones y fórmulas pluriverbales.

Zuluaga Ospina (1980) emprendió una especie de historiografía de la fraseología y destacó que las señas de identidad de las unidades fraseológicas eran la idiomaticidad y la fijación.

Eugenio Coseriu (1986), por su parte, efectuó una distinción entre "técnica del discurso" y "discurso repetido". En el marco de dicha taxonomía fraseológica, el estudioso considera que las combinaciones libres de palabras están clasificadas dentro de la técnica del discurso, mientras que las unidades fraseológicas se encuentran en la segunda categoría.

Tristá Pérez (1988) también en colaboración con Carneado Moré (1985), siguiendo la estela de la contribución de Casares, aplicó los criterios de la fraseología rusa a la española, llegando a la conclusión de que las unidades fraseológicas se pueden catalogar en dos tipos: en el primero, existe un elemento identificador dentro de la estructura interna del fraseologismo; en el segundo, el elemento identificador no está presente.

Años más tarde, Leonor Ruiz Gurillo (1998a) realizó una clasificación en la que se hacía hincapié en los distintos niveles de la lengua (fonético-fonológico, morfosintáctico, léxico-semántico y pragmático).

Finalmente, llegamos al Manual de fraseología española (1996) de Gloria Corpas Pastor que goza, en la actualidad, de gran relevancia a la hora de analizar el fenómeno fraseológico y que constituye la base bibliográfica de numerosos trabajos científicos. Esta estudiosa se distancia de los autores que la han precedido, aduciendo que las propuestas anteriores adolecían de falta de criterios clasificatorios claros. Corpas Pastor se centra en el concepto de enunciado, definiéndolo como sigue: «Una unidad de comunicación mínima, producto de un acto de habla, que corresponde generalmente a una oración simple o compuesta, pero que también puede constar de un sintagma o una palabra» (Corpas Pastor 1996: 51). La novedad aportada por la mencionada autora estriba en marcar tres esferas: la primera contiene las colocaciones; la segunda encierra las locuciones; mientras que dentro de la tercera esfera, hallamos los enunciados fraseológicos ${ }^{4}$.

3 Sin ánimo de ser exhaustivos, vamos a proponer una somera panorámica de los estudios más emblemáticos en el campo de la fraseología.

4 Para contar con un panorama más exhaustivo acerca de las definiciones y conceptos de colocaciones, locuciones y enunciados fraseológicos según la propuesta de Corpas Pastor, remitimos a su Manual de fraseología española (1996). 
Sin menospreciar la relevancia científica de cada una de las etiquetas terminológicas acuñadas por los autores antes citados, cuya aportación a los estudios fraseológicos ha sido paradigmática, cabe observar que nos hemos decantado por la denominación de unidad fraseológica por considerarla tan general como atinada para los efectos del presente estudio. Desde esta perspectiva, consideramos muy convincente la definición de María Valero Gisbert, según la cual se trata de:

expresiones que, en su origen, se han formado libremente a partir de las reglas del sistema lingüístico, y es entonces cuando gracias al uso repetido por parte de una comunidad lingüística, podrán consolidarse como unidades fraseológicas. Una característica que deriva de la anterior, es decir, de su alta frecuencia de uso, es la institucionalización. El uso repetido que los hablantes hacen de un determinado agrupamiento sin (o casi) alteración de la forma hace que se establezcan en la lengua, de este modo se llega a la fijación de la expresión en una forma determinada. (Valero Gisbert 2015: 1470)

Ahora bien, a la hora de efectuar comparaciones interlingüísticas, el fenómeno de la traducción adquiere su máxima expresión y la primera operación que cualquiera realizaría al toparse con una unidad fraseológica desconocida, sería traducirla a su propio idioma o, por lo menos, intentarlo. Es cierto que un porcentaje muy elevado de unidades fraseológicas surge como resultado directo de manifestaciones culturales e idiosincrásicas típicas de una determinada cultura, de ahí que la actividad traductora pueda resultar espinosa. Dicho en otras palabras, acecha el riesgo de no dar con una equivalencia acertada entre la expresión de la lengua $\mathrm{A}$ y la de la lengua $\mathrm{B}$. En el ámbito de la fraseología, más que hablar de traducción, sería conveniente hablar de una operación traslativa que consiste en reproducir lo más fielmente posible en la lengua de llegada el contenido semántico de una expresión. Tomemos como botón de muestra el célebre refrán español a cada cerdo le llega su San Martín ${ }^{5}$. Esta expresión indica que cada uno tendrá que pagar las consecuencias de sus propias acciones, especialmente si ha actuado mal. Si quisiéramos trasladar este refrán a otro idioma, sabríamos a ciencia cierta que de nada valdría adoptar una estrategia de traducción literal. Cualquier traductor bien formado sabe que se encuentra ante un refrán dotado de una carga idiomática y que tiene que recurrir a fuentes fiables que lo guíen en el proceso traductor. En este caso específico, contamos con una herramienta muy valiosa que cualquier profesional de la traducción se supone que conoce, un refranero multilingüe ${ }^{6}$, como el albergado en la página web del Centro Virtual del Instituto Cervantes. Esta herramienta lexicográfica en línea proporciona la siguiente traducción: chi la fa l'aspetti que, desde el punto de vista semántico, reproduce de manera bastante fiel el significado original. No obstante, el traductor no siempre tiene la misma suerte y puede haber casos en los cuales la labor documental se complica, al no presentar los diccionarios bilingües equivalencias traductológicas correctas, como veremos en lo sucesivo.

En el marco de la contrastividad entre lenguas afines como el español y el italiano, Paula Quiroga Munguía (2006) ha ofrecido una valiosa aportación al análisis traduc-

\footnotetext{
Este refrán hace referencia a la celebración de San Martín, el 11 de noviembre, fecha en la que suele dar inicio la matanza del cerdo.

6 Proporcionamos el enlace: https://cvc.cervantes.es/lengua/refranero/.
} 
tológico, especialmente por lo que se refiere a la problemática fraseológica. Los conceptos de equivalencia y correspondencia, de suma relevancia en los estudios de traducción, quedan nítidamente diferenciados en su obra. Podríamos decir que la correspondencia se sitúa en un plano lingüístico más superficial, mientras que la equivalencia va más allá y abarca más bien la dimensión idiosincrásica, esto es, el conjunto de formas populares, modismos y frases hechas que caracterizan el habla de una determinada comunidad de hablantes. Dicho en otros términos, la correspondencia conlleva una traducción más transparente, mientras que la equivalencia supone un proceso de reelaboración y reestructuración lingüística más complejo. A continuación, proponemos un esquema sencillo para ilustrar estas diferencias entre los dos conceptos:

\begin{tabular}{|l|l|l|}
\hline & \multicolumn{1}{|c|}{ ESPAÑL } & \multicolumn{1}{c|}{ ITALIANO } \\
\hline Correspondencia & Ahogarse en un vaso de agua & Perdersi in un bicchier d'acqua \\
\hline & Un clavo saca otro clavo & Chiodo schiaccia chiodo \\
\hline & Todos los caminos conducen a Roma & Tutte le strade portano a Roma \\
\hline Equivalencia & Quien se pica, ajos come & Avere la coda di paglia \\
\hline & No se hizo la miel para la boca del asno & Gettare le perle ai porci \\
\hline & Cada ollero alaba su puchero & Chi si loda si imbroda \\
\hline
\end{tabular}

Al abordar la traducción de la fraseología del italiano al español, Quiroga Munguía (2006: 145-146) pasa revista a un amplio abanico de técnicas y estrategias de traducción que, en nuestra opinión, también podrían resultar viables en la dirección español > italiano:

1. La traducción mediante otra UF que presenta la misma forma y el mismo significado que la del TO.

2. La traducción mediante otra UF equivalente de significado, pero diversa en algún otro aspecto.

3. La traducción mediante una paráfrasis.

4. La traducción de una UF por una unidad léxica simple equivalente en significado.

5. La traducción por omisión.

6. La traducción por compensación.

7. El préstamo.

8. El calco.

9. La nota del traductor.

Las nueve operaciones traductológicas que acabamos de mencionar se adecúan tanto a la labor de los lexicógrafos en la confección de los diccionarios bilingües como a la actividad traductora propiamente dicha, llevada a cabo por los profesionales de la mediación lingüística. En este caso, nos serviremos de ellas para el análisis traductológico que llevaremos a cabo con vistas a la categorización de las unidades fraseológico-idiomáticas relativas a las partes del cuerpo. 
Así y todo, no compartimos la postura de cuantos defienden la imposibilidad de traducir la fraseología. De alguna u otra manera, la investigación científica en el ámbito traductológico ha demostrado con creces que es posible trasladar, de una lengua origen a una lengua meta, cualquier formulación lingüística más o menos idiomática, aun a sabiendas de que los peligros acechan y de que se contempla la posibilidad de que se produzca un empobrecimiento en el plano semántico.

\section{La contribución de los diccionarios bilingües en el proceso de descodificación y traducción de las unidades fraseológicas}

El diccionario se configura como un instrumento de suma utilidad desde dos perspectivas: por un lado, en el proceso de aprendizaje de una lengua extranjera; por el otro, en la actividad traductora. Ante una palabra desconocida, lo primero que hacemos es acudir a un diccionario en busca de un equivalente ágil e inmediato que satisfaga nuestra curiosidad intelectual. Sin embargo, son muchas las razones por las cuales en numerosas ocasiones el diccionario, más que favorecer el correcto proceso de descodificación de una palabra o expresión, amenaza con complicarlo. Por un lado, cabe mencionar la escasa familiarización de los usuarios con esta herramienta, lo que acarrea un uso incorrecto o ineficaz. Por otra parte, no podemos ignorar las inexactitudes e imprecisiones presentes en muchas de estas obras lexicográficas bilingües, especialmente cuando se trata del tratamiento de unidades fraseológicas. A este respecto, no son pocas las ocasiones en las cuales aparecen en la estructura interna de los diccionarios bilingües expresiones y modimos que han caído en desuso y que, sin embargo, vienen presentados sin ninguna alusión a su vigencia. A este panorama, ya de por sí sombrío, se añade la falta de contextos de uso que faciliten información sobre la viabilidad pragmática y la eficacia comunicativa de las expresiones propuestas.

En un artículo que se remonta al año 2004, en el que se abordaba el papel de la fraseología en la lexicogafía monolingüe y bilingüe, Quiroga Munguía apuntaba que:

La fraseología sigue siendo la eterna ausente y, lamentablemente, el espacio reservado a tal fin no siempre está cubierto; es más, en un alto porcentaje de ocasiones lo encontramos vacío y allí donde hay contextualización, adolece en numerosos casos de falta de rigor científico en su selección y metodología, pues, como señala Heinz (1977: 214), en los diccionarios generalmente reina la anarquía por lo que se refiere a las UU.FF. y, en muchas ocasiones, no existe la posibilidad de encontrar una UF dada. (Quiroga Munguía 2004: 112)

Lo que planteaba la investigadora hace quince años era, por usar una UF, una verdad de Perogrullo. Sin embargo, hoy, creemos poder afirmar -sin temor a equivocarnos o a ser blanco de críticas- que la situación ha cambiado considerablemente a mejor:

El desarrollo que ha experimentado la lexicografía teórica y práctica a lo largo de estos casi cien años que nos separan del momento en que don Julio leyó su discurso nos ha llevado a adquirir más confianza en la configuración que debe tener un 
diccionario, a la vez que contamos con medios técnicos, antes impensables, para lograrlo. Como consecuencia de todo esto existe hoy la conciencia de que la realización de los diccionarios no puede estar en manos de amateurs, pues se requieren unos saberes lingüísticos que permitan desarrollar un trabajo que ha de optar, por un lado, por el conocimiento de la realidad del empleo de los términos y, por otro, por la posibilidad de aplicar a su descripción los modelos que expliquen de manera adecuada el significado y el uso de las palabras (Liverani / Pascual 2015: 9)

En el panorama lexicográfico relativo a la pareja de lenguas español-italiano los dos últimos decenios han sido prolíficos en materia de publicación de obras bilingües de gran envergadura, que se siguen usando hoy en día, gracias también a varios procesos de actualización terminológica y terminográfica.

Una aportación muy significativa al estudio de la lexicografía bilingüe procede de los postulados teóricos de Günter Haensch, quien brindó importantes pautas metodológicas acerca de cómo debería estar elaborado y estructurado un diccionario bilingüe que se precie. En un estudio publicado dieciséis años atrás, el estudioso observaba que hacía falta:

conseguir un equilibrio entre los materiales del lenguaje escrito y del lenguaje hablado. [...] además de contener el léxico no marcado o estándar y el de nivel elevado, debe recoger una serie de términos específicos que sean de dominio común, voces vulgares o malsonantes (consideradas tabúes), americanismos o extranjerismos de uso generalizado. (Haensch 2003: 81)

Entre los estudios directamente relacionados con el campo de la lexicografía bilingüe del par español-italiano, merecen una mención especial los llevados a cabo por Calvi (2002, 2003, 2006), Calvo Rigual (1996, 2016), Fusco (2006), Liverani (2004, 2008), Liverani y Pascual (2015), Quiroga Munguía (2004, 2006), San Vicente $(2006,2007,2008,2010)$ y Valero Gisbert $(2015,2016,2017)$. Dichas contribuciones aportan una visión crítico-metodológica en torno a la evolución de esta disciplina, poniendo de relieve la contrastividad lingüística y los aspectos peculiares que entran en juego en el tratamiento lexicográfico entre lenguas histórica y filogenéticamente emparentadas.

Sin duda alguna, es posible afirmar que uno de los criterios para evaluar la calidad de un diccionario bilingüe consiste en la presencia, a ser posible elevada, de unidades fraseológicas que conforman el acervo lingüístico de una comunidad de hablantes. Desde este punto de vista, prima el aspecto cualitativo antes que el cuantitativo. De nada serviría contar con un diccionario que contuviera la totalidad de unidades fraseológicas ${ }^{7}$ de una determinada lengua extranjera, si luego su transposición a la lengua meta resultara deficitaria o incluso errónea.

A propósito de cómo debería perfilarse un buen diccionario bilingüe españolitaliano, nos sumamos a las consideraciones de Baldissera:

Cabe destacar que sería impensable e imposible que un diccionario bilingüe contuviese todas las unidades fraseológicas, expresiones idiomáticas, refranes, modismos y fórmulas fijas de una lengua extranjera, pues el léxico de una lengua es el aspecto que evoluciona con más rapidez y al publicar una obra lexicográfica que ha requerido años y años de trabajo, la lengua habrá venido incorporando otras palabras y expresiones que conformen obras sucesivas. 
Un diccionario bilingüe de grandes dimensiones, lo digo de entrada, debería perfilarse como repertorio de la lengua de uso y, al mismo tiempo, como texto didáctico de consulta lingüística, con claras indicaciones sobre el funcionamiento y la estructura gramatical de los idiomas implicados, sin menoscabo de la primera función. Un DB italiano-español de gran tamaño, por tanto, no puede renegar de la presencia, masiva, de explicaciones gramaticales (en clave contrastiva, dada la gran afinidad morfosintáctica, caracterizada por sutiles diferencias a cualquier nivel, mucho más complicadas que los falsos amigos léxicos o de nivel elemental). Amén de abundar en informaciones y demás anotaciones lingüísticas (diafásicas, diastráticas, diacrónicas etcétera), culturales y pragmáticas. Y presentar una copiosa cuantía de fraseología y modismos, refranes y ejemplos concretos (incluso de autor, ¿por qué no?), para alcanzar una bidireccionalidad real y verdadera. (Baldissera 2015: 18)

Efectivamente, un repertorio lingüístico bilingüe válido ha de proporcionar toda la información lingüística clasificada según la categoría a la que pertenezca, poniendo un énfasis especial en la amplia gama de combinaciones léxicas y sintagmáticas que conforman el caudal fraseológico de una lengua. La lengua de Cervantes, pongamos un caso, es sumamente rica en manifestaciones lingüísticas de este tipo, de ahí que no se puedan infravalorar a la hora de introducirlas en una obra lexicográfica que pretenda erguirse como una valiosa herramienta de consulta. En el panorama lexicográfico monolingüe español, el Diccionario fraseológico del español actual (2004), cuidado por Manuel Seco supone, sin lugar a dudas, una aportación de gran envergadura. En lo que se refiere a la lengua italiana, no nos consta que existan obras de este tipo.

\section{Hacia una equivalencia traductológica: estudio lexicográfico bilingüe de unidades fraseológico-idiomáticas relacionadas con las partes del cuerpo}

Tras haber proporcionado el marco teórico en el que se desarrolla nuestra contribución, ha llegado el momento de adentrarnos en la parte más práctica de nuestro estudio, en la que procuraremos comprobar de forma fehaciente cómo se aborda la fraseología relativa a algunas partes del cuerpo ${ }^{8}$ en cuatro diccionarios bilingües español-italiano. Nuestra elección viene motivada por la amplia gama de combinaciones lingüístico-fraseológicas que se han venido formando a partir de este campo semántico.

\subsection{Metodología del estudio lexicográfico}

A los efectos del presente trabajo, nos hemos decantado por una metodología de descripción cualitativa, porque resulta pertinente en el análisis de los datos recabados a partir de los diccionarios bilingües. Para este estudio, en efecto, el análisis cuantitativo no sería idóneo por razones de espacio. Además del análisis cualitativo,

8 Cabe aclarar que bajo ningún concepto nuestro estudio se plantea desde la exhaustividad, por lo que la metodología por la que hemos optado no es de tipo cuantitativo, sino cualitativo. Tampoco hemos centrado la atención en la totalidad de las partes del cuerpo, porque la extensión del trabajo no lo hubiese permitido. 
también hemos optado por un método de investigación de tipo heurísico-especulativo, pues nos permitirá barajar y contrastar distintas hipótesis en lo concerniente a los resultados del rastreo fraseológico. Pues bien, antes de ilustrar cómo hemos decidido acometer nuestro estudio lexicográfico, vamos a presentar los cuatro diccionarios bilingües objeto de análisis:

\begin{tabular}{|l|c|l|l|}
\hline \multicolumn{1}{|c|}{ Autores } & Fecha & \multicolumn{1}{|c|}{ Título } & \multicolumn{1}{c|}{ Editorial } \\
\hline $\begin{array}{l}\text { Anna Giordano, } \\
\text { Cesáreo Calvo } \\
\text { Rigual }\end{array}$ & 2011 & $\begin{array}{l}\text { Dizionario Herder Italiano-Spagnolo / Español- } \\
\text { Italiano (edizione compatta) }\end{array}$ & Logos \\
\hline Laura Tam & 2009 & $\begin{array}{l}\text { Grande Dizionario di Spagnolo. Spagnolo- } \\
\text { Italiano / Italiano-Spagnolo }\end{array}$ & Hoepli \\
\hline AA.VV. & 2009 & $\begin{array}{l}\text { Grande Dizionario di Spagnolo. Spagnolo- } \\
\text { Italiano / Italiano-Spagnolo }\end{array}$ & Garzanti \\
\hline $\begin{array}{l}\text { Rossend Arqués, } \\
\text { Adriana Padoan }\end{array}$ & 2012 & $\begin{array}{l}\text { Il Grande dizionario di Spagnolo. Dizionario } \\
\text { Spagnolo-Italiano / Italiano-Español }\end{array}$ & $\begin{array}{l}\text { Zanichelli } \\
\text { Linguistica }\end{array}$ \\
\hline
\end{tabular}

La elección ha recaído sobre estos cuatro repertorios bilingües por situarse entre los más acreditados en el panorama actual de la lexicografía bilingüe y por presentar supuestamente ${ }^{9}$ las expresiones más comúnmente utilizadas en la sincronía actual.

En el plano metodológico, lo que haremos será bucear en la estructura interna de los mencionados diccionarios para comprobar si contienen la información semántica relativa a unidades fraseológico-idiomáticas inherentes a algunas partes del cuerpo $\mathrm{y}$, de paso, analizar su transposición al italiano. A continuación, señalamos las partes del cuerpo en las que hemos hecho hincapié:

\begin{tabular}{|l|l|l|l|l|}
\hline 1 Ojo & 5 Pelo & 9 Diente & 13 Cabeza & 17 Dedo \\
\hline 2 Mano & 6 Nariz & 10 Uña & 14 Hombro & 18 Cuello \\
\hline 3 Pie & 7 Brazo & 11 Espalda & 15 Oreja & 19 Ceja \\
\hline 4 Pierna & 8 Boca & 12 Cara & 16 Labio & 20 Codo \\
\hline
\end{tabular}

Son veinte en total las partes del cuerpo tomadas en consideración con vistas a nuestro estudio. Como ya hemos adelantado, la extensión de este artículo no permitiría un análisis cuantitativo exhaustivo, por lo que nos ceñiremos a un ejemplo para cada parte del cuerpo, con el fin de ofrecer una panorámica general del tema tratado. Ahora bien, después de comprobar si las expresiones buscadas están o no presentes en cada uno de los cuatro diccionarios, llevaremos a cabo un cotejo de las traducciones al italiano por si existen versiones alternativas. Por último, consultaremos un

9 El uso del adverbio "supuestamente" remite a que, a través de este trabajo lexicográfico, trataremos de confirmar o desmentir si los diccionarios analizados presentan información fraseológica actual, actualizada y en consonancia con las formas de decir de la lengua de llegada: el italiano. 
diccionario de la lengua italiana, a saber, il Dizionario della Lingua Italiana Treccani (2017), al objeto de cerciorarnos de que las equivalencias traductológicas propuestas están registradas en un diccionario actual de la lengua italiana y poder así considerarlas como una equivalencia acertada.

\subsection{Indicaciones metodológicas acerca del tratamiento de la fraseología en los diccionarios objeto de estudio}

Antes de emprender nuestro estudio lexicográfico, creemos conveniente aclarar que no es una casualidad que hayamos decidido focalizar nuestra atención en repertorios lexicográficos bilingües generales y no especializados en fraseología. El propósito es comprobar en qué medida está presente el acervo fraseológico de la lengua española y cómo está vertido al italiano en diccionarios donde se aborda la lengua en su totalidad, y no solo con respecto a aspectos específicos.

En el diccionario de Anna Giordano y Cesáreo Calvo Rigual (2011: 16), -que con respecto a los tres otros diccionarios consultados cuenta con una extensión inferiorno se hace una mención expresa al término "fraseología". En el apartado 1.6. de la introducción, sin embargo, se hace referencia al "tratamiento de modismos, locuciones, etc.":

Algunas expresiones están formadas por palabras que sólo se usan, precisamente, en dichas expresiones. Estos modismos se han introducido alfabéticamente teniendo en cuenta dicha palabra, que aparece seguida por dos puntos y por la expresión completa en letra negrita.

En los criterios generales del diccionario Garzanti (2009: ix) se especifica que: «Locuciones, modismos y refranes están destacados en negrita y colocados al final del artículo en un apartado introducido por el signo $\bullet \gg$.

En la presentación de Il Grande dizionario di Spagnolo (2012: 5) también se alude a la inclusión del fenómeno fraseológico como sigue:

Dado que una buena explicación de un término debe tener en cuenta la combinación del mismo con el resto de los elementos lingüísticos tanto en las expresiones comunes como en las idiomáticas, frecuentemente con grandes diferencias de significado respecto al literal, se ha dedicado particular atención a dichas combinaciones.

Por último, en las advertencias para la consulta de la tercera edición del diccionario de L. Tam (2009) -la que hemos consultado para nuestro estudio- se señala, en cambio, lo siguiente:

La fraseologia è estremamente eterogenea poiché comprende locuzioni, espressioni tecniche settoriali, modismi, forme colloquiali e proverbi. La fraseologia è preceduta da FRAS nella sezione Italiano-Spagnolo e da LOC nella sezione Spagnolo-Italiano.

En este último caso, es interesante notar cómo este diccionario adopta la etiqueta fraseologia en lo referente a la lengua italiana y, locuciones en la versión española. Ahora bien, una primera conclusión que se puede extraer y que consideramos muy 
alentadora, es el hecho de que en los cuatro diccionarios analizados el aspecto fraseológico tenga cabida, de ahí que podamos afirmar que la lexicografía moderna ha manifestado un claro interés hacia esta vertiente de la lengua.

\section{Análisis lexicográfico y traductológico de 20 unidades fraseológico-idiomáticas relacionadas con las partes del cuerpo}

En este apartado, presentamos los resultados del rastreo lexicográfico efectuado a partir de los cuatro diccionarios bilingües objeto de estudio. En las tablas que siguen, proporcionaremos de forma esquematizada la unidad fraseológico-idiomática objeto de estudio y el significado extraído del Diccionario de la Real Academia Española (DRAE), por emplear una obra de consulta general. A continuación, proponemos la equivalencia traductológica hallada en cada uno de los cuatro repertorios lexicográficos $\mathrm{y}$, al lado de cada versión, introduciremos la técnica o estrategia de traducción adoptada por los lexicógrafos, en función de la taxonomía propuesta por Quiroga Munguía (2006: 145-146).

Unidad fraseológico-idiomática 1: «ojo»

\begin{tabular}{|l|l|l|}
\hline \multicolumn{2}{|c|}{$\begin{array}{c}\text { "A ojo de buen cubero»: } \\
\text { Sin medida, sin peso y a bulto }\end{array}$} & \multicolumn{1}{c|}{ Técnica / estrategia de traducción } \\
\hline Herder & A occhio e croce & $\begin{array}{l}\text { Traducción mediante otra UF con significado } \\
\text { equivalente, pero diversa en algún otro aspecto }\end{array}$ \\
\hline Tam & A occhio e croce & $\begin{array}{l}\text { Traducción mediante otra UF con significado } \\
\text { equivalente, pero diversa en algún otro aspecto }\end{array}$ \\
\hline Garzanti & A occhio e croce & $\begin{array}{l}\text { Traducción mediante otra UF con significado } \\
\text { equivalente, pero diversa en algún otro aspecto }\end{array}$ \\
\hline Zanichelli & A occhio e croce & $\begin{array}{l}\text { Traducción mediante otra UF con significado } \\
\text { equivalente, pero diversa en algún otro aspecto }\end{array}$ \\
\hline
\end{tabular}

Unidad fraseológico-idiomática 2: «mano»

\begin{tabular}{|l|l|l|}
\hline \multicolumn{2}{|c|}{$\begin{array}{c}\text { «Ser mano de santo»: } \\
\text { Remedio que consigue del todo o prontamente } \\
\text { su efecto }\end{array}$} & \multicolumn{1}{c|}{ Técnica / estrategia de traducción } \\
\hline Herder & $\begin{array}{l}\text { Essere una mano benedetta } \\
\text { Tam }\end{array}$ & $\begin{array}{l}\text { Traducción mediante otra UF con significado } \\
\text { equivalente, pero diversa en algún otro aspecto }\end{array}$ \\
\hline Garzanti & Essere un toccasana & $\begin{array}{l}\text { Traducción de una UF por una unidad léxica } \\
\text { simple equivalente en significado }\end{array}$ \\
\hline Zanichelli & $\begin{array}{l}\text { Essere un toccasana / mano } \\
\text { santa }\end{array}$ & $\begin{array}{l}\text { Traducción mediante otra UF con significado } \\
\text { equivalente, pero diversa en algún otro aspecto }\end{array}$ \\
\hline
\end{tabular}


Unidad fraseológico-idiomática 3: «pie»

\begin{tabular}{|l|l|l|}
\hline \multicolumn{2}{|c|}{$\begin{array}{c}\text { «Saber de qué pie cojea uno»: } \\
\text { Conocer a fondo el vicio o defecto moral de } \\
\text { que adolece }\end{array}$} & Técnica / estrategia de traducción \\
\hline Herder & $\begin{array}{l}\text { Conoscere il punto debole di } \\
\text { qualcuno }\end{array}$ & Traducción mediante una paráfrasis \\
\hline Tam & Conoscere i difetti & Traducción mediante una paráfrasis \\
\hline Garzanti & $\begin{array}{l}\text { Conoscere il punto debole di } \\
\text { qualcuno }\end{array}$ & Traducción mediante una paráfrasis \\
\hline Zanichelli & $\begin{array}{l}\text { Sapere da che piede zoppica } \\
\text { qualcuno }\end{array}$ & Calco \\
\hline
\end{tabular}

Unidad fraseológico-idiomática 4: «pierna»

\begin{tabular}{|l|l|l|}
\hline \multicolumn{2}{|c|}{ Sin preocupación, tranquilamente } & \multicolumn{1}{c|}{ Técnica / estrategia de traducción } \\
\hline Herder & Dormire saporitamente & $\begin{array}{l}\text { Traducción mediante otra UF con significado } \\
\text { equivalente, pero diversa en algún otro aspecto }\end{array}$ \\
\hline Tam & Dormire come un ghiro & $\begin{array}{l}\text { Traducción mediante otra UF con significado } \\
\text { equivalente, pero diversa en algún otro aspecto }\end{array}$ \\
\hline Garzanti & $\begin{array}{l}\text { Dormire della grossa / dormire } \\
\text { come un ghiro }\end{array}$ & $\begin{array}{l}\text { Traducción mediante otra UF con significado } \\
\text { equivalente, pero diversa en algún otro aspecto }\end{array}$ \\
\hline Zanichelli & Dormire come un bambino & $\begin{array}{l}\text { Traducción mediante otra UF con significado } \\
\text { equivalente, pero diversa en algún otro aspecto }\end{array}$ \\
\hline
\end{tabular}

Unidad fraseológico-idiomática 5: «pelo»

\begin{tabular}{|l|l|l|}
\hline \multicolumn{2}{|c|}{$\begin{array}{c}\text { "Cuando las ranas críen pelo»: } \\
\text { Para dar a entender el tiempo remoto en el } \\
\text { que ejecutará algo, o que se duda de la } \\
\text { posibilidad de que suceda }\end{array}$} & Técnica / estrategia de traducción \\
\hline Herder & --------------- & $--------------~$ \\
\hline Tam & Quando gli asini voleranno & $\begin{array}{l}\text { Traducción mediante otra UF con significado } \\
\text { equivalente, pero diversa en algún otro aspecto }\end{array}$ \\
\hline Garzanti & Quando gli asini voleranno & $\begin{array}{l}\text { Traducción mediante otra UF con significado } \\
\text { equivalente, pero diversa en algún otro aspecto }\end{array}$ \\
\hline Zanichelli & Il giorno del mai & Traducción por compensación \\
\hline
\end{tabular}


Unidad fraseológico-idiomática 6: «nariz»

\begin{tabular}{|l|l|l|}
\hline \multicolumn{2}{|c|}{$\begin{array}{c}\text { «(Dejar) con un palmo de narices»: } \\
\text { Chasquearlo, privándolo de lo que esperaba } \\
\text { conseguir }\end{array}$} & Técnica / estrategia de traducción \\
\hline Herder & Lasciare con tanto di naso & $\begin{array}{l}\text { Traducción mediante otra UF que presenta la } \\
\text { misma forma y el mismo significado que la } \\
\text { del TO }\end{array}$ \\
\hline Tam & Lasciare con un palmo di naso & Calco \\
\hline Garzanti & Lasciare con un palmo di naso & Calco \\
\hline Zanichelli & Lasciare con un palmo di naso & Calco \\
\hline
\end{tabular}

Unidad fraseológico-idiomática 7: «brazo»

\begin{tabular}{|l|l|l|}
\hline \multicolumn{2}{|c|}{ «No dar su brazo a torcer»: } & Técnica / estrategia de traducción \\
\hline Rendirse, desistir de su dictamen o propósito & Non cedere & Traducción por compensación \\
\hline Tam & $\begin{array}{l}\text { Non spostarsi di un passo / una } \\
\text { virgola }\end{array}$ & Traducción mediante una paráfrasis \\
\hline Garzanti & Non darla vinta & Traducción por compensación \\
\hline Zanichelli & Non darla vinta & Traducción por compensación \\
\hline
\end{tabular}

Unidad fraseológico-idiomática 8: «boca»

\begin{tabular}{|l|l|l|}
\hline \multicolumn{2}{|c|}{$\begin{array}{c}\text { «No decir esta boca es mía»: } \\
\text { No hablar palabra }\end{array}$} & \multicolumn{1}{c|}{ Técnica / estrategia de traducción } \\
\hline Herder & Non aprire bocca & Traducción mediante una paráfrasis \\
\hline Tam & Non aprire bocca / non dire bè & Traducción mediante una paráfrasis \\
\hline Garzanti & Non aprire bocca & Traducción mediante una paráfrasis \\
\hline Zanichelli & Non aprire bocca / non fiatare & Traducción mediante una paráfrasis \\
\hline
\end{tabular}


Unidad fraseológico-idiomática 9: «diente»

\begin{tabular}{|l|l|l|}
\hline \multicolumn{2}{|c|}{$\begin{array}{c}\text { «Poner los dientes largos»: } \\
\text { Desear con vehemencia algo }\end{array}$} & \multicolumn{1}{c|}{ Técnica / estrategia de traducción } \\
\hline Herder & Far venire l'acquolina in bocca & Traducción por omisión \\
\hline Tam & Fare gola qualcosa & $\begin{array}{l}\text { Traducción mediante otra UF con significado } \\
\text { equivalente, pero diversa en algún otro aspecto }\end{array}$ \\
\hline Garzanti & $\begin{array}{l}\text { Far diventare verde dall'invidia / } \\
\text { Far venire l'acquolina in bocca }\end{array}$ & $\begin{array}{l}\text { Traducción mediante otra UF con significado } \\
\text { equivalente, pero diversa en algún otro aspecto } \\
\text { / Traducción por omisión }\end{array}$ \\
\hline Zanichelli & Venire l'acquolina in bocca & Traducción por omisión \\
\hline
\end{tabular}

Unidad fraseológico-idiomática 10: «uña»

\begin{tabular}{|l|l|l|}
\hline \multicolumn{2}{|c|}{$\begin{array}{c}\text { «Ser uña y carne»: } \\
\text { Haber estrecha amistad }\end{array}$} & \multicolumn{1}{c|}{ Técnica / estrategia de traducción } \\
\hline Herder & Essere unghia e carne & Calco \\
\hline Tam & Essere amici per la pelle & $\begin{array}{l}\text { Traducción mediante otra UF con significado } \\
\text { equivalente, pero diversa en algún otro aspecto }\end{array}$ \\
\hline Garzanti & Essere pappa e ciccia & $\begin{array}{l}\text { Traducción mediante otra UF con significado } \\
\text { equivalente, pero diversa en algún otro aspecto }\end{array}$ \\
\hline Zanichelli & Essere pappa e ciccia & $\begin{array}{l}\text { Traducción mediante otra UF con significado } \\
\text { equivalente, pero diversa en algún otro aspecto }\end{array}$ \\
\hline
\end{tabular}

Unidad fraseológico-idiomática 11: «espalda»

\begin{tabular}{|l|l|l|}
\hline «Donde la espalda pierde su honesto nombre»: & \multicolumn{1}{|c|}{ El trasero } & Técnica / estrategia de traducción \\
\hline Herder & Nelle natiche & Traducción mediante una paráfrasis \\
\hline Tam & Il fondoschiena & Traducción mediante una paráfrasis \\
\hline Garzanti & Il didietro / il fondoschiena & Traducción mediante una paráfrasis \\
\hline Zanichelli & Dove non batte il sole & $\begin{array}{l}\text { Traducción mediante otra UF con significado } \\
\text { equivalente, pero diversa en algún otro aspecto }\end{array}$ \\
\hline
\end{tabular}


Unidad fraseológico-idiomática 12: «cara»

\begin{tabular}{|l|l|l|}
\hline \multicolumn{2}{|c|}{$\begin{array}{c}\text { "Tener más cara que espalda»: } \\
\text { Tener gran desfachatez o desvergüenza }\end{array}$} & \multicolumn{1}{c|}{ Técnica / estrategia de traducción } \\
\hline Herder & --------------- & --------------- \\
\hline Tam & $\begin{array}{l}\text { Avere una bella faccia tosta / di } \\
\text { bronzo }\end{array}$ & $\begin{array}{l}\text { Traducción mediante otra UF con significado } \\
\text { equivalente, pero diversa en algún otro aspecto }\end{array}$ \\
\hline Garzanti & Avere una bella faccia tosta & $\begin{array}{l}\text { Traducción mediante otra UF con significado } \\
\text { equivalente, pero diversa en algún otro aspecto }\end{array}$ \\
\hline Zanichelli & Avere una faccia di tolla & $\begin{array}{l}\text { Traducción mediante otra UF con significado } \\
\text { equivalente, pero diversa en algún otro aspecto }\end{array}$ \\
\hline
\end{tabular}

Unidad fraseológico-idiomática 13: «cabeza»

\begin{tabular}{|l|l|l|}
\hline \multicolumn{2}{|c|}{$\begin{array}{c}\text { (Tener la cabeza llena de pájaros»: } \\
\text { Tener fantasías o ilusiones infundadas }\end{array}$} & \multicolumn{1}{c|}{ Técnica / estrategia de traducción } \\
\hline Herder & Avere dei grilli per la testa & $\begin{array}{l}\text { Traducción mediante otra UF con significado } \\
\text { equivalente, pero diversa en algún otro aspecto }\end{array}$ \\
\hline Tam & Avere la testa piena di grilli & $\begin{array}{l}\text { Traducción mediante otra UF con significado } \\
\text { equivalente, pero diversa en algún otro aspecto }\end{array}$ \\
\hline Garzanti & Avere grilli per la testa & $\begin{array}{l}\text { Traducción mediante otra UF con significado } \\
\text { equivalente, pero diversa en algún otro aspecto }\end{array}$ \\
\hline Zanichelli & Avere dei grilli per la testa & $\begin{array}{l}\text { Traducción mediante otra UF con significado } \\
\text { equivalente, pero diversa en algún otro aspecto }\end{array}$ \\
\hline
\end{tabular}

Unidad fraseológico-idiomática 14: «hombro»

\begin{tabular}{|l|l|l|}
\hline \multicolumn{1}{|c|}{$\begin{array}{c}\text { "Arrimar el hombro»: } \\
\text { Trabajar con actividad, ayudar o contribuir } \\
\text { al logro de un fin }\end{array}$} & \multicolumn{1}{c|}{ Técnica / estrategia de traducción } \\
\hline Herder & Lavorare / aiutare alacremente & Traducción mediante una paráfrasis \\
\hline Tam & Aiutare / collaborare & Traducción mediante una paráfrasis \\
\hline Garzanti & Dare una mano & Traducción por compensación \\
\hline Zanichelli & $\begin{array}{l}\text { Mettersi al lavoro / rompersi la } \\
\text { schiena }\end{array}$ & Traducción mediante una paráfrasis \\
\hline
\end{tabular}


Unidad fraseológico-idiomática 15: «oreja»

\begin{tabular}{|l|l|l|}
\hline \multicolumn{2}{|c|}{$\begin{array}{c}\text { «Estar con la mosca detrás de la oreja»: } \\
\text { Con recelo o con prevención para evitar algo }\end{array}$} & \multicolumn{1}{c|}{ Técnica / estrategia de traducción } \\
\hline Herder & Avere la pulce nell'orecchio & $\begin{array}{l}\text { Traducción mediante otra UF con significado } \\
\text { equivalente, pero diversa en algún otro aspecto }\end{array}$ \\
\hline Tam & Avere la pulce nell'orecchio & $\begin{array}{l}\text { Traducción mediante otra UF con significado } \\
\text { equivalente, pero diversa en algún otro aspecto }\end{array}$ \\
\hline Garzanti & Avere la pulce nell'orecchio & $\begin{array}{l}\text { Traducción mediante otra UF con significado } \\
\text { equivalente, pero diversa en algún otro aspecto }\end{array}$ \\
\hline Zanichelli & Essere sospettoso & Traducción mediante una paráfrasis \\
\hline
\end{tabular}

Unidad fraseológico-idiomática 16: «labio»

\begin{tabular}{|l|l|l|}
\hline \multicolumn{2}{|c|}{$\begin{array}{c}\text { "Quedarse con la miel en los labios»: } \\
\text { Privarle de lo que empezaba a gustar } \\
\text { y disfrutar }\end{array}$} & \multicolumn{1}{c|}{ Técnica / estrategia de traducción } \\
\hline Herder & Far restare con la voglia & Traducción mediante una paráfrasis \\
\hline Tam & Lasciare con la voglia & Traducción mediante una paráfrasis \\
\hline Garzanti & Lasciare a bocca asciutta & $\begin{array}{l}\text { Traducción mediante otra UF con significado } \\
\text { equivalente, pero diversa en algún otro aspecto }\end{array}$ \\
\hline Zanichelli & $\begin{array}{l}\text { Lasciare con l'acquolina in } \\
\text { bocca }\end{array}$ & $\begin{array}{l}\text { Traducción mediante otra UF con significado } \\
\text { equivalente, pero diversa en algún otro aspecto }\end{array}$ \\
\hline
\end{tabular}

Unidad fraseológico-idiomática 17: «dedo»

\begin{tabular}{|l|l|l|}
\hline \multicolumn{2}{|c|}{$\begin{array}{c}\text { «No tener dos dedos de frente»: } \\
\text { Ser de poco entendimiento o juicio }\end{array}$} & \multicolumn{1}{c|}{ Técnica / estrategia de traducción } \\
\hline Herder & Avere poco cervello & Traducción mediante una paráfrasis \\
\hline Tam & $\begin{array}{l}\text { Avere il cervello di una gallina / } \\
\text { non avere sale in zucca }\end{array}$ & $\begin{array}{l}\text { Traducción mediante otra UF con significado } \\
\text { equivalente, pero diversa en algún otro aspecto }\end{array}$ \\
\hline Garzanti & $\begin{array}{l}\text { Avere un cervello di una gallina } \\
\text { / avere poca testa }\end{array}$ & $\begin{array}{l}\text { Traducción mediante otra UF con significado } \\
\text { equivalente, pero diversa en algún otro aspecto } \\
\text { / Traducción mediante una paráfrasis }\end{array}$ \\
\hline Zanichelli & $\begin{array}{l}\text { Non distinguere il bianco dal } \\
\text { nero / avere poco cervello }\end{array}$ & $\begin{array}{l}\text { Traducción mediante otra UF con significado } \\
\text { equivalente, pero diversa en algún otro aspecto } \\
\text { / Traducción mediante una paráfrasis }\end{array}$ \\
\hline
\end{tabular}


Unidad fraseológico-idiomática 18: «cuello»

\begin{tabular}{|l|l|l|}
\hline \multicolumn{2}{|c|}{ «Estar con la soga al cuello»: } & \multicolumn{1}{c|}{ Técnica / estrategia de traducción } \\
\hline Herder & Essere con la corda al collo & $\begin{array}{l}\text { Traducción mediante otra UF que presenta la } \\
\text { misma forma y el mismo significado que la } \\
\text { del TO }\end{array}$ \\
\hline Tam & Essere in un mare di guai & $\begin{array}{l}\text { Traducción mediante otra UF con significado } \\
\text { equivalente, pero diversa en algún otro aspecto }\end{array}$ \\
\hline Garzanti & Essere con la corda al collo & $\begin{array}{l}\text { Traducción mediante otra UF que presenta la } \\
\text { misma forma y el mismo significado que la } \\
\text { del TO }\end{array}$ \\
\hline Zanichelli & $\begin{array}{l}\text { Avere l'acqua alla gola / essere } \\
\text { alla canna del gas }\end{array}$ & $\begin{array}{l}\text { Traducción mediante otra UF con significado } \\
\text { equivalente, pero diversa en algún otro aspecto }\end{array}$ \\
\hline
\end{tabular}

Unidad fraseológico-idiomática 19: «ceja»

\begin{tabular}{|l|l|l|}
\hline \multicolumn{2}{|c|}{$\begin{array}{c}\text { «Tener (algo / a alguien) entre ceja y ceja»: } \\
\text { Mirarlo con prevención desfavorable / tener } \\
\text { como pensamiento o propósito fijos }\end{array}$} & Técnica / estrategia de traducción \\
\hline Herder & Avercela con qualcuno & Traducción mediante una paráfrasis \\
\hline Tam & $\begin{array}{l}\text { Ficcarsi in capo / in testa } \\
\text { qualcosa }\end{array}$ & $\begin{array}{l}\text { Traducción mediante otra UF con significado } \\
\text { equivalente, pero diversa en algún otro aspecto }\end{array}$ \\
\hline Garzanti & Avercela con qualcuno & Traducción mediante una paráfrasis \\
\hline Zanichelli & Avere il chiodo fisso & Traducción por compensación \\
\hline
\end{tabular}

Unidad fraseológico-idiomática 20: «codo»

\begin{tabular}{|l|l|l|}
\hline \multicolumn{2}{|c|}{$\begin{array}{c}\text { «Hablar por los codos»: } \\
\text { Hablar demasiado }\end{array}$} & \multicolumn{1}{c|}{ Técnica / estrategia de traducción } \\
\hline Herder & Essere chiacchierone & $\begin{array}{l}\text { Traducción de una UF por una unidad léxica } \\
\text { simple equivalente en significado }\end{array}$ \\
\hline Tam & Essere un chiacchierone & $\begin{array}{l}\text { Traducción de una UF por una unidad léxica } \\
\text { simple equivalente en significado }\end{array}$ \\
\hline Garzanti & Essere un chiacchierone & $\begin{array}{l}\text { Traducción de una UF por una unidad léxica } \\
\text { simple equivalente en significado }\end{array}$ \\
\hline Zanichelli & Non stancarsi mai di parlare & Traducción por compensación \\
\hline
\end{tabular}




\section{Comentario sobre el estudio lexicográfico y consideraciones finales}

Antes de concluir, nos parece oportuno efectuar un breve cotejo y comentario sobre las equivalencias traductológicas encontradas a lo largo de este rastreo lexicográfico, prestando igualmente atención a la correspondencia que se puede establecer entre las equivalencias traductológicas dadas en italiano y el sentido original de la unidad fraseológico-idiomática, tal y como se recoge en el Diccionario de la Real Academia Española (DRAE):

\begin{tabular}{|c|c|c|}
\hline $\begin{array}{l}\text { Unidad fraseológico- } \\
\text { idiomática }\end{array}$ & Comentario & $\begin{array}{l}\text { Correspondencia con } \\
\text { la definición del DRAE }\end{array}$ \\
\hline $\begin{array}{l}\text { Unidad 1: «A ojo de } \\
\text { buen cubero» }\end{array}$ & $\begin{array}{l}\text { Los cuatro diccionarios }{ }^{10} \text { presentan la } \\
\text { misma equivalencia traductológica, que está } \\
\text { registrada en los diccionarios de la lengua } \\
\text { italiana. }\end{array}$ & $\begin{array}{l}\text { Herder: Sí } \\
\text { Tam: Sí } \\
\text { Garzanti: Sí } \\
\text { Zanichelli: Sí }\end{array}$ \\
\hline $\begin{array}{l}\text { Unidad 2: «Ser mano de } \\
\text { santo» }\end{array}$ & $\begin{array}{l}\text { H. y T. presentan la misma equivalencia } \\
\text { traductológica al igual que } \mathrm{Zn} \text { y Gz. Se } \\
\text { notan leves variaciones y tanto T. como } \mathrm{Zn} \\
\text { presentan dos equivalencias más. }\end{array}$ & $\begin{array}{l}\text { Herder: Sí } \\
\text { Tam: Sí } \\
\text { Garzanti: Sí } \\
\text { Zanichelli: Sí }\end{array}$ \\
\hline $\begin{array}{l}\text { Unidad 3: «Saber de } \\
\text { qué pie cojea uno» }\end{array}$ & $\begin{array}{l}\text { H. y Gz optan por la misma equivalencia } \\
\text { traductológica; T. parafrasea el significado de } \\
\text { la expresión original y Zn efectúa un calco, } \\
\text { pues la versión traducida de este último } \\
\text { diccionario no se encuentra registrada en } \\
\text { ningún diccionario monolingüe italiano. }\end{array}$ & $\begin{array}{l}\text { Herder: Sí } \\
\text { Tam: Sí } \\
\text { Garzanti: Sí } \\
\text { Zanichelli: Sí }\end{array}$ \\
\hline $\begin{array}{l}\text { Unidad 4: «Dormir a } \\
\text { pierna suelta» }\end{array}$ & $\begin{array}{l}\text { Los cuatro diccionarios presentan cuatro } \\
\text { equivalencias distintas, pero todas } \\
\text { semánticamente correctas. Cabe observar que } \\
\text { con respecto a los otros tres diccionarios, Gz } \\
\text { cuenta con dos equivalencias traductológicas. }\end{array}$ & $\begin{array}{l}\text { Herder: Sí } \\
\text { Tam: Sí } \\
\text { Garzanti: Sí } \\
\text { Zanichelli: Sí }\end{array}$ \\
\hline $\begin{array}{l}\text { Unidad 5: «Cuando las } \\
\text { ranas críen pelo» }\end{array}$ & $\begin{array}{l}\text { H. no presenta ninguna equivalencia. T. y } \\
\text { Gz. optan por la misma solución traductora, } \\
\text { que de alguna manera exhibe una estructura } \\
\text { sintáctica parecida a la italiana, mientras } \\
\text { que Zn. se decanta por una compensación } \\
\text { que, sin embargo, nada le resta al significado } \\
\text { idiomático de la expresión. }\end{array}$ & $\begin{array}{l}\text { Herder: No presente } \\
\text { Tam: Sí } \\
\text { Garzanti: Sí } \\
\text { Zanichelli: Sí }\end{array}$ \\
\hline $\begin{array}{l}\text { Unidad 6: «(Dejar) con } \\
\text { un palmo de narices» }\end{array}$ & $\begin{array}{l}\text { H. es el único diccionario que ofrece una } \\
\text { equivalencia distinta de los otros tres que, } \\
\text { por su parte, calcan la formulación original. } \\
\text { Así y todo, las equivalencias traductológicas } \\
\text { propuestas están registradas en la lengua } \\
\text { italiana. }\end{array}$ & $\begin{array}{l}\text { Herder: Sí } \\
\text { Tam: Sí } \\
\text { Garzanti: Sí } \\
\text { Zanichelli: Sí }\end{array}$ \\
\hline
\end{tabular}

10 Por motivos prácticos, al hacer referencia a los cuatro diccionarios consultados, utilizaremos las siguientes etiquetas: Herder (H.); Tam (T.); Garzanti (Gz); Zanichelli (Zn). 


\begin{tabular}{|c|c|c|}
\hline $\begin{array}{c}\text { Unidad fraseológico- } \\
\text { idiomática }\end{array}$ & Comentario & $\begin{array}{l}\text { Correspondencia con } \\
\text { la definición del DRAE }\end{array}$ \\
\hline $\begin{array}{l}\text { Unidad 7: «No dar su } \\
\text { brazo a torcer» }\end{array}$ & $\begin{array}{l}\text { Gz y Zn tienen la misma equivalencia } \\
\text { traductológica, mientras que H. y T. usan } \\
\text { unidades fraseológicas distintas y, además, } \\
\text { T. propone dos equivalencias. Las cuatro } \\
\text { opciones traductológicas son correctas en } \\
\text { italiano. }\end{array}$ & $\begin{array}{l}\text { Herder: Sí } \\
\text { Tam: Sí } \\
\text { Garzanti: Sí } \\
\text { Zanichelli: Sí }\end{array}$ \\
\hline $\begin{array}{l}\text { Unidad 8: «No decir } \\
\text { esta boca es mía» }\end{array}$ & $\begin{array}{l}\text { Los cuatro diccionarios eligen la misma } \\
\text { equivalencia traductológica que resulta } \\
\text { comunicativamente eficaz en italiano, aunque } \\
\text { pierda algo del carácter idiomático. Además, } \\
\text { cabe señalar que el T. y Zn brindan una } \\
\text { segunda equivalencia. }\end{array}$ & $\begin{array}{l}\text { Herder: Sí } \\
\text { Tam: Sí } \\
\text { Garzanti: Sí } \\
\text { Zanichelli: Sí }\end{array}$ \\
\hline $\begin{array}{l}\text { Unidad 9: «Poner los } \\
\text { dientes largos» }\end{array}$ & $\begin{array}{l}\text { H., Gz y Zn proponen la misma equivalencia } \\
\text { traductológica; en T., por su parte, se cambia } \\
\text { de equivalente, sin alteración alguna en } \\
\text { términos de significado. Asimismo, Gz } \\
\text { propone una equivalencia más, con carácter } \\
\text { idiomático en italiano. }\end{array}$ & $\begin{array}{l}\text { Herder: No } \\
\text { Tam: Sí } \\
\text { Garzanti: Sí } \\
\text { Zanichelli: No }\end{array}$ \\
\hline $\begin{array}{l}\text { Unidad 10: «Ser uña y } \\
\text { carne» }\end{array}$ & $\begin{array}{l}\text { Todos los diccionarios excepto H. ofrecen } \\
\text { una equilavencia traductológica correcta. En } \\
\text { H. hay un calco, pues la expresión propuesta } \\
\text { no se usa en absoluto en italiano. }\end{array}$ & $\begin{array}{l}\text { Herder: No } \\
\text { Tam: Sí } \\
\text { Garzanti: Sí } \\
\text { Zanichelli: Sí }\end{array}$ \\
\hline $\begin{array}{l}\text { Unidad 11: «Donde } \\
\text { la espalda pierde su } \\
\text { honesto nombre» }\end{array}$ & $\begin{array}{l}\text { Esta larga expresión española encuentra } \\
\text { una equivalencia traductológica en una } \\
\text { unidad léxica simple en H., T. y Gz. Zn es } \\
\text { el único repertorio en el que se reproduce la } \\
\text { vertiente fraseológico-idiomática, mediante } \\
\text { una equivalencia más formal y con carácter } \\
\text { literario. }\end{array}$ & $\begin{array}{l}\text { Herder: Sí } \\
\text { Tam: Sí } \\
\text { Garzanti: Sí } \\
\text { Zanichelli: Sí }\end{array}$ \\
\hline $\begin{array}{l}\text { Unidad 12: «Tener más } \\
\text { cara que espalda» }\end{array}$ & $\begin{array}{l}\text { T. y Gz proponen la misma equivalencia } \\
\text { traductológica; Zn opta por una equivalencia } \\
\text { poco difundida en el italiano actual. En H. no } \\
\text { hay huella de la locución estudiada. }\end{array}$ & $\begin{array}{l}\text { Herder: No presente } \\
\text { Tam: Sí } \\
\text { Garzanti: Sí } \\
\text { Zanichelli: Sí }\end{array}$ \\
\hline $\begin{array}{l}\text { Unidad 13: «Tener } \\
\text { la cabeza llena de } \\
\text { pájaros» }\end{array}$ & $\begin{array}{l}\text { Los cuatro diccionarios están de acuerdo en } \\
\text { proporcionar todos la misma equivalencia } \\
\text { traductológica, que se configura como una } \\
\text { expresión idiomática en italiano. }\end{array}$ & $\begin{array}{l}\text { Herder: Sí } \\
\text { Tam: Sí } \\
\text { Garzanti: Sí } \\
\text { Zanichelli: Sí }\end{array}$ \\
\hline $\begin{array}{l}\text { Unidad 14: «Arrimar el } \\
\text { hombro» }\end{array}$ & $\begin{array}{l}\text { Los cuatro diccionarios presentan } \\
\text { equivalencias traductológicas más o menos } \\
\text { acordes a la definición del DRAE, si bien su } \\
\text { traducción pierda de alguna forma el carácter } \\
\text { idiomático. }\end{array}$ & $\begin{array}{l}\text { Herder: Sí } \\
\text { Tam: Sí } \\
\text { Garzanti: Sí } \\
\text { Zanichelli: Sí }\end{array}$ \\
\hline
\end{tabular}




\begin{tabular}{|c|c|c|}
\hline $\begin{array}{c}\text { Unidad fraseológico- } \\
\text { idiomática }\end{array}$ & Comentario & $\begin{array}{l}\text { Correspondencia con } \\
\text { la definición del DRAE }\end{array}$ \\
\hline $\begin{array}{l}\text { Unidad 15: «Estar con } \\
\text { la mosca detrás de la } \\
\text { oreja» }\end{array}$ & $\begin{array}{l}\text { H., T. y Gz ofrecen una equivalencia } \\
\text { traductológica totalmente en línea con el } \\
\text { sentido original. Zn, por su parte, neutraliza } \\
\text { el carácter idiomático mediante una } \\
\text { paráfrasis. }\end{array}$ & $\begin{array}{l}\text { Herder: Sí } \\
\text { Tam: Sí } \\
\text { Garzanti: Sí } \\
\text { Zanichelli: Sí }\end{array}$ \\
\hline $\begin{array}{l}\text { Unidad 16: «Quedarse } \\
\text { con la miel en los } \\
\text { labios» }\end{array}$ & $\begin{array}{l}\text { En este caso, los cuatro diccionarios } \\
\text { presentan cuatro equivalencias } \\
\text { traductológicas casi idénticas. Lo que cambia } \\
\text { es el uso de los verbos adoptados. En Zn } \\
\text { se hace una clara referencia al ámbito de la } \\
\text { comida. }\end{array}$ & $\begin{array}{l}\text { Herder: Sí } \\
\text { Tam: Sí } \\
\text { Garzanti: Sí } \\
\text { Zanichelli: Sí }\end{array}$ \\
\hline $\begin{array}{l}\text { Unidad 17: «No tener } \\
\text { dos dedos de frente» }\end{array}$ & $\begin{array}{l}\text { H. hace una paráfrasis de la expresión, } \\
\text { mientras que T. y Gz. se decantan por la } \\
\text { misma equivalencia y Zn. adopta otra } \\
\text { distinta, si bien la idiomaticidad está presente } \\
\text { en las tres versiones. }\end{array}$ & $\begin{array}{l}\text { Herder: Sí } \\
\text { Tam: Sí } \\
\text { Garzanti: Sí } \\
\text { Zanichelli: Sí }\end{array}$ \\
\hline $\begin{array}{l}\text { Unidad 18: «Estar con } \\
\text { la soga al cuello» }\end{array}$ & $\begin{array}{l}\text { H. y Gz ofrecen la misma equivalencia } \\
\text { traductológica, mientras que } \mathrm{T} \text {. y } \mathrm{Zn} \text { presentan } \\
\text { otra. De todos modos, en los cuatro casos, } \\
\text { la fijación y la idiomaticidad caracterizan a } \\
\text { las cuatro versiones, con lo que se mantiene } \\
\text { fidelidad a la expresión original. }\end{array}$ & $\begin{array}{l}\text { Herder: Sí } \\
\text { Tam: Sí } \\
\text { Garzanti: Sí } \\
\text { Zanichelli: Sí }\end{array}$ \\
\hline $\begin{array}{l}\text { Unidad 19: «Tener } \\
\text { (algo / a alguien) entre } \\
\text { ceja y ceja» }\end{array}$ & $\begin{array}{l}\text { H. y Gz tienen la misma equivalencia en } \\
\text { italiano, mientras que T. y Zn proponen } \\
\text { traducciones con el mismo significado, } \\
\text { pero estructura distinta. En este caso, es } \\
\text { interesante notar que H. y G. solo ofrecen } \\
\text { la equivalencia de la primera acepción, } \\
\text { mientras que T. y Zn solo la relativa a la } \\
\text { segunda. }\end{array}$ & $\begin{array}{l}\text { Herder: Sí } \\
\text { Tam: Sí } \\
\text { Garzanti: Sí } \\
\text { Zanichelli: Sí }\end{array}$ \\
\hline $\begin{array}{l}\text { Unidad 20: «Hablar por } \\
\text { los codos» }\end{array}$ & $\begin{array}{l}\text { H., T. y Gz ofrecen la misma equivalencia } \\
\text { traductológica mediante la adopción de una } \\
\text { unidad léxica simple. Zn, en cambio, sin } \\
\text { restar nada al sentido original, lleva a cabo } \\
\text { una compensación. }\end{array}$ & $\begin{array}{l}\text { Herder: Sí } \\
\text { Tam: Sí } \\
\text { Garzanti: Sí } \\
\text { Zanichelli: Sí }\end{array}$ \\
\hline
\end{tabular}

En términos generales, resulta claro que las técnicas de traducción más empleadas en el acto transpositivo son la traducción mediante otra UF que presenta la misma forma y el mismo significado que la del TO y la traducción mediante otra UF equivalente en términos de significado, pero diversa en algún otro aspecto, aunque haya casos de paráfrasis, compensación y calco.

En cierto modo, los resultados recabados a raíz del estudio lexicográfico resultan alentadores de cara a la inclusión de ítems fraseológicos en los repertorios lexicográficos bilingües actuales, pues de los veinte casos estudiados se da casi en su totalidad 
una correspondencia semántica entre la definición en español y las versiones traducidas al italiano.

Como primera consideración, es importante poner de relieve un aspecto de calado, esto es, que los diccionarios H. y T. solo proporcionan la equivalencia traductológica a secas, mientras que el Gz y el $\mathrm{Zn}$ ofrecen en muchas ocasiones ejemplos contextualizados que permiten al usuario descodificar con más agilidad en qué casos usar la unidad fraseológica en cuestión. Entre estos dos últimos diccionarios, el Zn es el más rico en contextos de uso.

En segundo lugar, es interesante notar que las veinte unidades buscadas cuentan con una equivalencia traductológica. Además, los diccionarios consultados presentan una equivalencia para todas las expresiones buscadas, excepto H., donde faltan tres, lo que, de todas maneras, no se puede considerar un demérito dada la magnitud del acervo fraseológico-idiomático con el que cuenta un idioma. Lo que sí llama la atención es lo que podríamos calificar como "variabilidad traductológica", pues en los cuatro repertorios consultados no son pocos los casos en los que las unidades fraseológicoidiomáticas analizadas encuentran equivalencias distintas. Incluso hay casos en los que las cuatro equivalencias traductológicas son totalmente distintas (unidad 4). En la mayoría de las ocasiones, las formulaciones lingüísticas halladas presentan estructuras morfosintácticas diferentes, lo que hace plausible barajar la hipótesis de que para las elecciones léxico-semánticas y morfosintácticas se ha recurrido a fuentes lexicográficas monolingües muy variadas. Sin embargo, en honor a la verdad, también hemos descubierto casos de equivalencias traductológicas idénticas (unidades 1-6-8). Asimismo, es muy positivo constatar que en el $90 \%$ de los casos se dan equivalencias totales, mientras que el restante $10 \%$ se puede dividir entre equivalencias parciales y nulas. En este último caso, se ha registrado un solo caso de equivalencia nula (unidad 10: equivalencia propuesta en $\mathrm{Zn}$ ). En general puede afirmarse que la equivalencia traductológica en la dirección español > italiano se ha logrado, aunque a veces quede relegado a un segundo plano el carácter idiomático de las unidades fraseológicas, produciéndose así una neutralización fraseológica en el marco del proceso de traducción. Lo que sí se echa en falta, como adelantábamos, es la inclusión de contextos de uso que posibiliten, por parte del usuario, una correcta descodificación del significado de las numerosísimas combinaciones léxicas y sintagmáticas que caracterizan el universo fraseológico de cualquier idioma, a partir de sus componentes más sencillos. Por todo lo anterior, sería deseable que los lexicógrafos prestaran más atención a este aspecto peculiar de la redacción de obras bilingües. Por último, si tuviéramos que dar una respuesta al interrogante que se planteaba en el título de esta contribución, podríamos concluir que a día de hoy los repertorios lexicográficos bilingües con los que contamos, ofrecen una valiosa aportación a la hora de llevar a cabo operaciones de descodificación y traducción de unidades fraseológicas con un carácter idiomático más o menos marcado. Como se desprende claramente de nuestro estudio lexicográfico, las obras consultadas proporcionan información fraseológico-idiomática con un elevado grado de equivalencia traductológica, aun sin tratarse de diccionarios fraseológicos e idiomáticos. Es esta la razón por la que también en lo que atañe a la lengua española, nuestro punto de referencia no ha sido el diccionario de Seco et al. (2004) sino el DRAE, por ser una obra de consulta general, al igual que los cuatro diccionarios español-italiano consultados para nuestro estudio.

Es muy probable que en estos momentos se estén acometiendo procesos de revisión y/o actualización de repertorios lexicográficos bilingües ya existentes, o bien se 
estén confeccionando nuevos. Además de agradecer a los lexicógrafos su encomiable labor, confiamos en que estudios como el que acabamos de presentar constituyan para ellos un motivo de reflexión válido de cara a una puesta al día cada vez más eficaz desde el punto de vista de la comunicación cotidiana y de los varios ámbitos sociales, culturales y profesionales en los que se desarrolla la lengua, así como la incorporación del caudal fraseológico e idiomático del español. El valor añadido, a nuestro modo de ver, estribaría en poner especial énfasis en una perspectiva de comparación con el italiano que vaya más allá de la superficie textual para abordar el fenómeno fraseológico desde la contrastividad con mayor rigor. Los resultados que se cosecharían a raíz de un análisis más escrupuloso orientado al tratamiento fraseológico, redundarían en beneficio de una mejor sistematización y categorización del léxico en sus combinaciones simples, complejas y sintagmáticas.

\section{Referencias bibliográficas}

Baldissera, Andrea (2015): «Hacia un gran diccionario español-italiano / italiano-español: observaciones crítico-metodológicas sobre tres diccionarios mayores», Cuadernos Aispi. Lexicografía, Fraseología y Terminología, 6, pp. 15-36.

Calvi, Maria Vittoria (2002): «Lessicografia bilingue italo-spagnola e didattica del lessico», en E. Ferrario, V. Pulcini (eds.), La lessicografia bilingue tra presente e avvenire, Vercelli, Mercurio, pp. 123-137.

Calvi, Maria Vittoria (2003): «La lexicografía bilingüe de español e italiano», en M. V. Calvi, F. San Vicente (eds.), Didáctica del léxico y nuevas tecnologías, Viareggio-Lucca, Mauro Baroni Editore, pp. 39-53.

Calvi, Maria Vittoria (2006): «Il componente culturale nel dizionario Ambruzzi di spagnolo e italiano», en F. San Vicente (ed.), Lessicografia bilingue e traduzione, Monza, Polimetrica Publisher, pp. 83-101.

Calvo Rigual, Cesáreo (1996): «Sobre lexicografía ítalo-española reciente», Actas del V Congreso de Italianistas Españoles II Novecento, Oviedo, Universidad de Oviedo, pp. 145-161.

Calvo Rigual, Cesáreo (2016): «La lexicografía monolingüe española e italiana cara a cara: aspectos editoriales», en R. Cotelo García (coord.), Bordeando los márgenes: gramática, lenguaje técnico y otras cuestiones fronterizas en los estudios lexicográficos del español, San Millán de la Cogolla, Cilengua, Centro Internacional de Investigación de la Lengua Española, pp. 61-83.

Carbonell i Cortés, Ovidi (1997): «Del "conocimiento del mundo" al discurso ideológico: el papel del traductor como mediador entre culturas», en E. Morilla, y J. P. Arias (eds.), $E l$ papel del traductor, Salamanca, Ediciones Colegio de España, pp. 59-74.

Carneado Moré, Zola / Tristá Pérez, Antonia Mª (1985): Estudios de fraseología, La Habana, Academia de Ciencias de Cuba.

Casares, Julio (1992) [1950]: Introducción a la lexicografia moderna, tercera edición, Madrid, Colección Textos Universitarios, 17, Consejo Superior de Investigaciones Científicas.

Corpas Pastor, Gloria (1996): Manual de fraseología española, Madrid, Gredos.

Corpas Pastor, Gloria (2000): «Acerca de la (in)traducibilidad de la fraseología», en G. Corpas Pastor (ed.), Las lenguas de Europa: estudios de fraseología, fraseografía y traducción, Granada, Editorial Comares, pp. 483-522.

Corpas Pastor, Gloria (2003): Diez años de investigación en fraseología: análisis sintácticosemánticos, contrastivos y traductológicos, Madrid, Iberoamericana. 
Coseriu, Eugenio (1986): Principios de semántica estructural, Madrid, Gredos.

Fusco, Fabiana (2006): «Dalla linguistica alla traduttologia: i repertori lessicografici», en F. San Vicente (ed.), Lessicografia bilingue e traduzione, Monza, Polimetrica Publisher, pp. 19-34.

García-Page Sánchez, M. (2008): Introducción a la fraseología española, Rubí (Barcelona), Anthropos Editorial.

Haensch, Günther (2003): «Los diccionarios bilingües en el umbral del siglo XXI. La lexicografía bilingüe en la actualidad y su valoración», en M. A. Martín Zorraquino, J. L. Aliaga Jiménez (eds.), La lexicografía hispánica en el siglo XXI: balance y perspectivas, Zaragoza, Gobierno de Aragón, Departamento de Educación, Cultura y Deporte/Institución "Fernando el Católico", pp. 77-89.

Iamartino, Giovanni (2006): «Dal lessicografo al traduttore: un sogno che si realizza?», en F. San Vicente (ed.), Lessicografia bilingue e traduzione, Monza, Polimetrica Publisher, pp. 101-132.

Liverani, Elena (2004): «La lessicografia bilingue di derivazione nebrisense: il dizionario di Landucci», en D. A. Cusato et. al., La memoria delle lingue, la didattica e lo studio delle lingue della penisola iberica in Italia, Actas del XXI Congreso, Associazione Ispanisti Italiani, Messina, Andrea Lippolis, pp. 137-151.

Liverani, Elena (2008): «Il grande dizionario di spagnolo-italiano, italiano-spagnolo (2004) de L. Tam», en F. San Vicente (ed.), Textos fundamentales de la lexicografía italoespañola (1917-2007), Monza, Polimetrica International Scientific Publisher, II, pp. 439-494.

Liverani, Elena / Pascual, José Antonio (2015): «Introducción», Cuadernos AISPI. Lexicografia, Fraseología y Terminología, 6, pp. 9-16.

Martínez Marín, Juan (1996): Estudios de fraseología española, Málaga, Ágora.

Quiroga Munguía, Paula (2004): «Fraseología y lexicografía: el tratamiento de la fraseología en los diccionarios bilingües generales italiano/español del siglo XX», Revista de lexicografía, 11, pp. 105-147.

Quiroga Munguía, Paula (2006): Fraseología ítalo-española. Aspectos de lingüística aplicada y contrastiva, Granada, Método.

Ruiz Gurillo, Leonor (1998a): «Una clasificación no directa de las unidades fraseológicas del español» en G. Wotjak (coord.), Estudios de fraseología y fraseografía del español actual, Madrid, Iberoamericana, pp. 13-37.

Ruiz Gurillo, Leonor (1998b): La fraseología del español coloquial, Barcelona, Editorial Ariel S.A.

San Vicente, Félix (ed.) (2006): Lessicografia bilingue e traduzione: metodi, strumenti, approcci attuali, Monza, Polimetrica.

San Vicente, Félix (ed.) (2007): Perfiles para la historia y crítica de la lexicografía bilingüe del español, Monza, Polimetrica International Scientific Publisher.

San Vicente, Félix (ed.) (2008): Textos fundamentales de la lexicografía italoespañola (19172007), Monza, Polimetrica International Scientific Publisher.

San Vicente, Félix (ed.) (2010): Textos fundamentales de la lexicografía italoespañola (19051916), Monza, Polimetrica International Scientifical Publisher.

Tristá Pérez, Antonia María (1988): Fraseología y contexto, La Habana, Editorial de Ciencias Sociales.

Valero Gisbert, María (2015): «Capítulo XLIX: La fraseología», en Félix San Vicente (dir. y coord.), GREIT. Gramática de referencia de español para italófonos. III. Oración, discurso, léxico, Bologna/Salamanca, Clueb/Universidad de Salamanca, pp. 1468-1476. 
Valero Gisbert, María (2016): «Fraseología y marcas diacrónicas en la lexicografía bilingüe de los diccionarios más representativos de español/italiano del s. XXI», en I. Sariego López, J. Gutiérrez Cuadrado, C. Garriga Escribano (eds.), El diccionario en la encrucijada: de la sintaxis y la cultura al desafio digital, Santander, Universidad de Cantabria, pp. 395-411.

Valero Gisbert, María (2017): «La fraseología en la L2 a través de la lexicografía bilingüe», en M. J. Domínguez Vázquez, M. T. Sanmarco Bande (eds.), Lexicografía y didáctica. Diccionarios y otros recursos lexicográficos en el aula, New York, Peter Lang, pp. 399-413.

Zuluaga Ospina, Alberto (1980): Introducción al Estudio de las Expresiones Fijas, Frankfurt a.M. Bern, Cirencester/UK, Lang.

\subsection{Diccionarios bilingües español-italiano consultados}

Arqués, Rossend / Padoan, Adriana (2012): Il Grande dizionario di Apagnolo. Dizionario Spagnolo-Italiano / Italiano-Español, Bolonia, Zanichelli.

Giordano, Anna / Calvo Rigual, Cesáreo (2011): Dizionario Italiano-Spagnolo / EspañolItaliano, Barcelona, Herder Editorial.

Tam, Laura (2009): Grande Dizionario di Spagnolo. Spagnolo-Italiano / Italiano-Spagnolo, Milano, Hoepli.

VV.AA (2009): Grande Dizionario di Spagnolo. Spagnolo-Italiano Italiano-Spagnolo, Levis (TN), Garzanti Linguistica.

\subsection{Diccionarios bilingües "antiguos"}

Ambruzzi, Lucio (1949): Nuovo dizionario spagnolo-italiano, italiano-spagnolo, Torino, Paravia.

Carbonell, Sebastián (1950-1957): Dizionario fraseologico completo italiano-spagnolo e spagnolo-italiano, Milano, Hoepli.

Frisoni, Gaetano (1917-1927): Dizionario moderno italiano-spagnuolo e spagnuolo-italiano, Milano, Hoepli.

Martínez Amador, Emilio María (1957): Diccionario Italiano-Español y Español-Italiano, Barcelona, Sopena.

\subsection{Diccionarios monolingües y fraseológicos}

Seco, Manuel / Andrés Olimpia / Ramos, Gabino (2004): Diccionario fraseológico documentado del español actual. Locuciones y modimos españoles, Madrid, Santillana.

Dizionario della lingua italiana Treccani, Firenze, Giunti T.V.P. Editori.

\subsection{Webgrafía}

Centro Virtual Cervantes, https://cvc.cervantes.es/lengua/refranero/

Diccionario de la Lengua Española, http://dle.rae.es/?w=diccionario 